Received: 30.05 .2018

Revised: 03.05.2019

Accepted: 28.06 .2019

DOI: $10.17804 / 2410-9908.2019 .3 .052-056$

\title{
INFLUENCE OF LONG-TERM OPERATION ON THE STRUCTURE AND IMPACT TOUGHNESS OF THE 09Mn2Si PIPE STEEL
}

\author{
I. V. Vlasov ${ }^{1, a)^{*}}$, S. V. Panin ${ }^{1,2, \text { b) }}$, P. O. Marushchak ${ }^{3, \text { c) }}$, A. V. Eremin ${ }^{1, \text { d) }}$, A. V. Byakov ${ }^{1, \text { e) }}$ \\ ${ }^{1}$ Institute of Strength Physics and Materials Science SB RAS, \\ 2/4 Akademicheskii ave., Tomsk, 634055, Russian Federation \\ ${ }^{2}$ National Research Tomsk Polytechnic University, 30 Lenina Ave., Tomsk, 634050, Russian Federation \\ ${ }^{3}$ Ternopil Ivan Puluj National Technical University, 56 Ruska St., Ternopil, 46001, Ukraine \\ a) iD https://orcid.org/0000-0001-9110-8313 viv@ispms.tsc.ru; \\ b) iD https://orcid.org/0000-0001-7623-7360 svp@ispms.tsc.ru; \\ c) iD https://orcid.org/0000-0002-3001-0512 $ه$ maruschak.tu.edu@gmail.com; \\ d) iD https://orcid.org/0000-0002-1800-9818 ave@ispms.tsc.ru; \\ e) Scopus ID: 34879419100 bjakov@ispms.tsc.ru \\ ${ }^{*}$ Corresponding author. E-mail: vlasov.ilya.viktorovich@gmail.com \\ Address for correspondence: 2/4, pr. Akademicheskii, Tomsk, 634055, Russian Federation \\ Tel.: +7 (3822)286 828; fax: +7 (3822) 492576
}

The microstructure and mechanical properties of the $09 \mathrm{Mn} 2 \mathrm{Si}$ steel used for construction of the Mastakh-Berge-Yakutsk natural gas transportation pipeline are investigated comprehensively after 37 years of operation. The results obtained for the specimens cut out from the pipe are compared to those obtained using emergency stock (reference) specimens. It is demonstrated that longterm operation in harsh climate does change the microstructure appreciably. Strain aging, however, can be identified through precipitation of finely dispersed carbides in the bulk grains, and hydrogen charging may occur in the steel, which gives rise to partial decarburization. The latter causes some embrittlement of the steel, measured under impact loading. The revealed microstructural changes do not practically affect static tension or hardness properties. This can be attributed to the development of two competing processes: i) softening as a result of decarburization and ii) hardening due to pinning of dislocations on carbide precipitates. The microstructure degradation results in sharp reduction of impact toughness, which drops by a factor of two at temperatures below zero Centigrade. The decrease in crack resistance under impact bending is primarily related to service-induced embrittlement accompanied by a pronounced decrease in the maximum load under which the main crack initiates. The reasons and mechanisms of the observed phenomena are discussed.

Keywords: pipe steel, impact toughness, structure degradation.

\section{Introduction}

Main oil and gas pipelines are strategic industrial facilities. Monitoring their structural integrity is of crucial importance. Safe operation of a pipeline over several decades assumes comprehensive understanding of the reasons for the degradation its microstructure. These studies are of particular importance for oil and gas pipelines operating for a long period of time in the Far North, where the annual temperature variation may reach $100^{\circ} \mathrm{C}[1]$.

The degradation of the 09Mn2Si structural steel used for constricting a main gas pipeline for 37 years is investigated in this paper. For low-carbon ferrite-pearlite pipe steel that operates under low temperatures, the ductile-to-brittle transition leading to a sharp decrease in the impact tough- 
ness is of particular concern [2]. Impact testing provides the most common express way of assessing fracture toughness. The study was performed to explore the strength, ductility and (impact) fracture toughness of the 09Mn2Si steel taken from a line section of the gas pipeline after 37 years of service. Similar studies were carried out for the same steel taken from the reserve stock of pipes.

\section{Experimental}

Specimens of the 09Mn2Si steel were cut out by an electric discharge machine from fragments of two pipes: after long-term operation (from 1972 to 2009) and from the reference unloaded pipe that was stored in the field as "emergency stock" within the same time in accordance with industry practice. Dog-bone shaped specimens sized $50 \times 7 \times 1 \mathrm{~mm}^{3}$, with a gauge part of $20 \times 5 \times 1 \mathrm{~mm}^{3}$, were employed for the testing.

Impact toughness was measured according to the ASTM E 23-07 standard by the Charpy technique using $55 \times 7 \times 7 \mathrm{~mm}^{3}$ specimens having a V-shaped notch with a depth of $2 \mathrm{~mm}$. An instrumented Instron 450MPX impact pendulum was employed. The tests were carried out at $T=+20,0,-20,-40$ and $-70^{\circ} \mathrm{C}$. The specimens were cooled in a Lauda RP 870 chiller for $10 \mathrm{~min}$ before testing. The time lag between specimen removal from the cooling chamber and impact loading did not exceed $5 \mathrm{~s}$.

The pearlite fraction was estimated on etched specimens by the JMicroVision software. Etching was carried out in a 5\% nitric acid solution. The mean size of ferrite grains was determined according to the ASTM E 112-96 standard. The microhardness was measured by a PMT-3 Vickers tester at $0.98 \mathrm{~N}$. The $H B$ hardness was measured by a TSh $2 \mathrm{M}$ hardness tester at $7857 \mathrm{~N}$ (the diameter of the ball was $5 \mathrm{~mm}$ ). The $H V$ hardness was measured by a PT-7R-1 hardness tester at $490.3 \mathrm{~N}$. The fine microstructure was investigated by a Philips SM-12 transmission electron microscope.

\section{Results}

The measurement of pipe wall thickness for both types of steels has shown that 37 years of service result in an approximately $0.4 \mathrm{~mm}$ wall thickness reduction. The reference steel has a ferrite-pearlite structure, typical of hot-rolled sheets (Fig. 1 a). The pearlite content amounts to $16 \pm 1 \%$. The average grain size is found to be $9.5 \pm 1 \mu \mathrm{m}$. The steel after use also possesses a ferrite-pearlite structure though the fraction of pearlite has reduced to about $12 \pm 0.6 \%$; pearlite colonies appear to be small and located mainly along the grain boundaries (Fig. $1 \mathrm{~b}$ ). The average grain size in this reference steel is equal to $11 \pm 1 \mu \mathrm{m}$.

Thus, during operation, the fraction of the pearlite phases in the 09Mn2Si steel decreases by $\sim 5 \%$. The reasons responsible for these changes can be the influence of long-term exposure to a hydrogen-contacting medium. The reduction of the carbon content is also accompanied by a slight increase in the ferrite grain size (by $\sim 10 \%$ ).

A typical ferrite structure with cementite plates along the grain boundaries in both examined steel fragments was observed with the help of transmission electron microscopy. Large equiaxial cementite particles (100 to $500 \mathrm{~nm}$ ) are located both in the bulk grains and at the grain boundaries (Fig. $1 \mathrm{c}$ ). The dislocation density for the reference steel is higher, $10^{10}$ to $10^{11} \mathrm{~cm}^{-2}$, while it is lower by an order of magnitude, i.e. $10^{9}$ to $10^{10} \mathrm{~cm}^{-2}$, after use (Fig. $1 \mathrm{~d}$ ).

It is known from $[3,4]$ that long-term operation of steel may give rise to both abovementioned hydrogen charging and microstructure changes. The latter reveal themselves through such multiple processes as deformation and failure of cementite particles along the boundaries of ferrite grains, formation of carbide precipitates, and evolution of the dislocation substructure involving strain aging. The strain aging phenomenon in steels is commonly associated with carbon segregation at dislocation cores leading to the formation of Cottrell atmospheres, pinning the dislocations. Natural gas transportation pipeline systems are designed with a large safety factor assuming operation for dozens of years. 


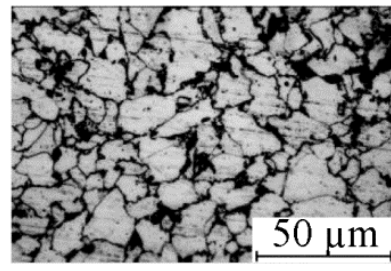

a

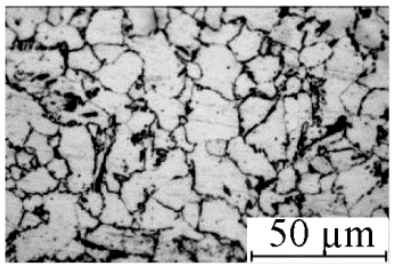

b

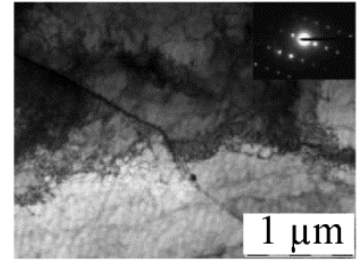

c

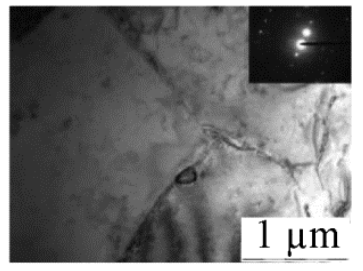

d

Fig. 1. Optical images of the microstructure of the 09Mn2Si steel (a, b); bright-field TEM micrographs $(c, d)$; the reference material $(a, c)$; the specimen after long-term operation $(b, d)$

For this reason, the steel is not supposed to experience significant stresses or overloads during operation, which may potentially give rise to large plastic deformation and dynamic strain aging. Thus, it can be assumed that strain aging could occur only at the initial stage of service, this being corroborated by the approximately one-order difference in the total dislocation density between the reference material and the one after operation. These changes do not exert a significant effect on mechanical properties including hardness, but they may decrease impact toughness.

The microhardness measured on the flat surface of the reference material and the one after use is equal to $H \mu=1.84 \pm 0.05 \mathrm{GPa}$ and $1.95 \pm 0.05 \mathrm{GPa}$, respectively. The hardness of the specimens of both types differs within the regular scatter and amounts to $126 \mathrm{HB}$ (135 HV) and $131 \mathrm{HB}$ (134 $H V)$, respectively.

The results obtained for the steel after the long-term operation can be rationalized in terms of competition between two co-existing processes: i) hardness decrease as a result of decarburization and ii) strain hardening due to dislocations pinning by carbon atoms. When balanced, these processes can maintain the steel hardness after the operation close to the initial level, while a different deformation behavior can be anticipated if compared to the reference steel.

An upper yield point and the Lüders plateau are observed on the loading diagrams of the 09Mn2Si steel specimens in both states (Fig. 2 a). It agrees well with the results of TEM observations showing low dislocation density at the beginning of plastic flow [5]. Specimens of both types exhibit similar values of the lower and upper yield stresses and ultimate tensile strength. However, the reference specimens have appreciably higher ductility. This difference in ductility is likely to be due to a larger volume of the pearlite phase.

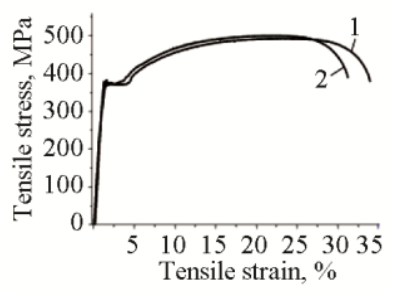

a

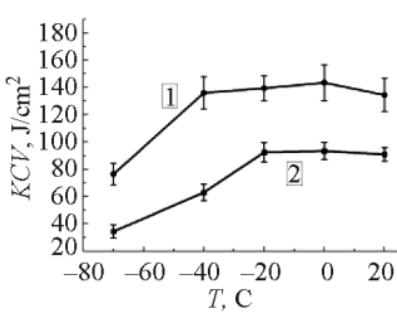

b

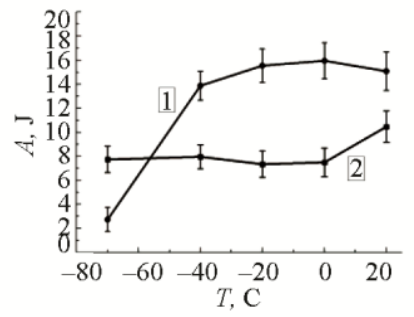

$\mathrm{c}$

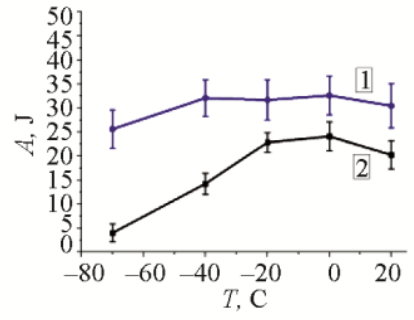

d

Fig. 2. Tensile diagrams for 09Mn2Si steel (a); impact toughness (b); energy of crack initiation (c); crack propagation energy vs. temperature (d): 1 - reference material; 2 - after long-term service

The impact toughness of the 09Mn2Si steel after many years of service under the cold climate conditions has decreased significantly in comparison with the reference steel for all the test temperatures (Fig. 2 b). The brittle-to-ductile transition for this steel starts at $T=-20{ }^{\circ} \mathrm{C}$, while it begins at a lower temperature, $T=-40{ }^{\circ} \mathrm{C}$, for the reference stock steel (Fig. 2 b). The increase in the brittle-to-ductile transition temperature in the steel after the service is caused by structural degradation accompanied by decarburization and strain hardening, as was noted above. 
The mechanical energy for crack initiation and propagation has been estimated for the specimens of both types during impact testing (Fig. $2 \mathrm{c}, \mathrm{d}$ ). The highest values of the mechanical energy $A_{\text {I }}$ extended for the crack initiation stage are observed in the reference stock steel. The $A(T)$ curve drops sharply in the region of brittle-to-ductile transition, which is not seen for the steel after the service (Fig. 2 c). The energy of crack propagation for the reference steel is also higher (Fig. 2 d). However, unlike the initiation stage, a significant decrease in $A(T)$ is seen for both steels at the brittle-to-ductile transition.

\section{Conclusion}

A thorough study has been performed to characterize the strength, ductility, and impact toughness of the 09Mn2Si pipe steel used in a line section of the Mastakh-Berge-Yakutsk Arctic natural gas pipeline with a diameter of $530 \mathrm{~mm}$ and a wall thickness of $7 \mathrm{~mm}$ (after 37 years of service). Similar studies and comparative analysis of results have been carried out for the same steel taken from the reserve stock.

It has been shown that long-term service does not give rise to significant changes of the cementite phase. This is attributed to low pressure and low temperature. However, hydrogen charging may occur, giving rise to a partial decarburization of the steel. Strain aging is slightly pronounced and manifested as the precipitation of fine carbides in the bulk grains, which causes embrittlement in impact bending tests.

The revealed degradation exerts only little effect on mechanical properties measured under static tension and in hardness measurements. This can be due to the development of two competing processes: i) softening as a result of decarburization and ii) hardening due to pinning of dislocations on carbide precipitates.

The impact fracture toughness of the 09Mn2Si steel under study decreases more significantly in contrast to tensile or fatigue properties at ambient temperature. The maximum impact fracture toughness decreases by a factor of $\sim 2.2$ at $T=-70{ }^{\circ} \mathrm{C}$. The decrease in crack resistance under impact bending is primarily caused by service-induced embrittlement accompanied by a pronounced decrease in the maximum load under which the main crack initiates. Thus, fracture toughness appears as the parameter which, among others, is most sensitive to microstructural changes induced within the 37 years of operation. Overall, the observed degradation of properties is attributed primarily to reduced macroscopic and local ductility due to a gradual accumulation of defects in the material during operation under harsh Arctic conditions.

\section{Acknowledgments}

The work was performed in the framework of the fundamental research Program of the Russian State Academies of Sciences for 2013-2020, line of research III.23, with a partial support from RFBR Grants No. 18-08-00516_a, 18-38-00679 and RF President Council Grant for the support of leading research schools NSh-5875.2018.8. Impact bending tests were carried out at the National Research Tomsk Polytechnic University within the framework of the Competitiveness Enhancement Program of Tomsk Polytechnic University.

\section{References}

1. Panin V.E., Derevyagina L.S., Lebedev M.P., Syromyatnikova A.S., Surikova N.S., Pochivalov Yu.I., Ovechkin B.B.Scientific Basis for Cold Brittleness of Structural BCC Steels and Their Structural Degradation at Below Zero Temperatures. Phys. Mesomech., 2017, vol. 2 (2), pp. 125-133. DOI: 10.1134/S1029959917020023.

2. Nastich S.Yu., Soya S.V., Molostov M.A., Vasiliev I.S., Dyakonova N.B. Effect of temperature for the start of finish rolling on coiled steel X70 microstructure and cold resistance. Metallurgist, 2012, vol. 56 (7), pp. 519-525. DOI: 10.1007/s11015-012-9608-6. 
3. Nykyforchyn H., Lunarska E., Tsyrulnyk O.T., Nikiforov K., Genarro M.E., Gabetta G. Environmentally assisted "in-bulk" steel degradation of long term service gas trunkline. Engineering Failure Analysis, 2010, vol. 17 (3), pp. 624-632. DOI: 10.1016/j.engfailanal.2009.04.007.

4. Meshkov Yu.Ya., Shyyan A.V., Zvirko O.I. Evaluation of the In-service degradation of steels of gas pipelines according to the criterion of mechanical stability. Materials Science, 2015, vol. 50 (6), pp. 830-835. DOI: 10.1007/s11003-015-9790-3.

5. Yasnii P.V., Glad'o V.B., Okipnyi I.B. Relationship between rupture stress and microstructure parameters of plastically deformed heat-resistant steel. Strength of Materials, 2007, vol. 39 (4), pp. 349-357. 